\title{
Vardenafil: The clinical trial experience
}

\author{
Peter J Pommerville MD FRCSC
}

\begin{abstract}
PJ Pommerville. Vardenafil: The clinical trial experience. J Sex Reprod Med 2003;3(1):15-21.

Vardenafil is a new phosphodiesterase 5 inhibitor designed specifically to be an effective and safe oral treatment for erectile dysfunction (ED). The present review provides a broad overview, with emphasis placed on results from key studies that will impact patient and physician choice of an appropriate treatment for ED. In addition to being highly selective for phosphodiesterase 5, vardenafil shows strong efficacy in the broad range of ED patients, regardless of age, etiology or severity, or concomitant disorders (eg, diabetes). This, combined with a good cardiovascular safety profile and the added features of minimal interactions with food and alcohol, indicates that vardenafil is very likely to play an important role in the overall management of ED.
\end{abstract}

Key Words: Cardiovascular safety; Clinical studies; Diabetes; Erectile dysfunction; Impotence; Penis; Phosphodiesterase inhibitor; Prostatectomy; Vardenafil

Sexual function in men is shaped by biochemical, psychoOlogical and social influences. In recent years, ongoing research and treatment of one aspect of male sexual dysfunction, namely loss of erectile capability, has gained considerable attention (World Health Organization [WHO] - International Society for Impotence Research [ISIR] First International Consultation on Erectile Dysfunction, 1999). Erectile dysfunction (ED) is defined as the consistent or recurrent inability to attain or maintain a penile erection sufficient for sexual performance. A number of studies have been published that provide estimates of the prevalence in aging men. These include the Massachusetts Male Aging Study (1), the Cologne Male Survey (2) and the prevalence of ED in Columbia, Ecuador and Venezuela study (3). More recently, in Canada, a national survey was conducted to estimate erectile function $(\mathrm{EF})$ in sexually active men, the ease of communicating about sexual concerns with partners and physicians, and the impact of ED on a patient's well-being $(4,5)$. This study, supported by the Canadian Male Sexual Health Council, was conducted in most regions of the country and included 3009 men and women. The prevalence of ED in Canada was estimated to be $27 \%$ in sexually active men, and was highest in the Prairies and British Columbia. Sexual issues were generally difficult to discuss with partners, and only $17 \%$ of men and $21 \%$ of women with sexual concerns discussed them with their physicians. Of those who reported having ED, only one in four spoke to a doctor about it, even though it may have had a significant impact on quality of life. However, if the physician was to initiate the query regarding EF, $80 \%$ of men with ED who had not consulted a medical professional would acknowledge and discuss the

\section{Vardénafil : l'expérience des essais cliniques}

RÉSUMÉ : Le vardénafil est un nouvel inhibiteur de la phosphodiestérase 5 , conçu expressément pour traiter de façon sûre et efficace, par voie orale, la dysérection. Le présent examen donne un aperçu général de la situation, tout en mettant l'accent sur les résultats des principales études qui influenceront le choix des patients et des médecins quant à une forme appropriée de traitement de la dysérection. En plus de s'avérer un inhibiteur fortement sélectif de la phosphodiestérase 5, le vardénafil se montre très efficace chez un large éventail de patients, peu importe l'âge, l'étiologie ou le degré de gravité de la dysérection ou encore les troubles concomitants (ex. : le diabète). Compte tenu du fait que ce médicament offre une bonne marge d'innocuité cardiovasculaire et qu'il produit très peu d'interactions avec la nourriture et l'alcool, le vardénafil est destiné à jouer un rôle important dans le traitement global de la dysérection. problem. With this in mind, it should be noted that a recently published survey showed that $40 \%$ of Canadian primary care physicians do not initiate any screening questions on sexual health (6). This was partially because of discomfort in taking a patient's sexual history. Based on these studies and others, it is clear that ED is a prevalent condition and opportunities exist to improve patient and health professional interactions.

EF can be compromised by a number of disease states and medications and, therefore, affects a broad range of patients. For example, it is well known that organic causes of ED include pathologies that arise from diabetes mellitus (7) and hypertension (8) or treatment for prostate cancer either by radical prostatectomy (9) or radiation therapy (10).

Guidelines on the treatment of ED, including the WHO ISIR First International Consultation on ED and the Canadian Urological Association 2002 newsletter guidelines, recommend a trial with oral medication as first line treatment (11). Oral medications currently available include phosphodiesterase 5 (PDE5) inhibitors such as sildenafil, or centrally acting agents such as apomorphine (not available in North America).

Sildenafil, which is currently on the market almost worldwide, demonstrates good efficacy and safety $(12,13)$. However, even with these features, a high rate of dissatisfaction and discontinuation of treatment is reported. Only about 39\% of patients receiving sildenafil renewed their prescriptions after one year (14). Discontinuation rates range from $14 \%$ up to $47 \%$. It is evident that there is room for additional therapies that may provide a better efficacy profile or have other more suitable properties. Indeed, some of the characteristics for an 
TABLE 1

Comparison of inhibition of PDE activity by sildenafil and vardenafil

\begin{tabular}{lcc}
\hline PDE & $\begin{array}{c}\text { Sildenafil } \\
\mathbf{I C}_{50}, \boldsymbol{\mu M}\end{array}$ & $\begin{array}{c}\text { Vardenafil } \\
\mathbf{I C}_{\mathbf{5 0}}, \boldsymbol{\mu M}\end{array}$ \\
\hline PDE1C $^{1}$ & 0.350 & 0.121 \\
PDE2A $^{1}$ & $>10$ & $>10$ \\
PDE3B $^{1}$ & $>10$ & 2.68 \\
PDE4B $^{1}$ & 2.9 & 1.91 \\
PDE5A $^{1}$ & 0.012 & 0.00081 \\
PDE7B $^{1}$ & $>10$ & 4.60 \\
PDE10 $^{1}$ & 3.8 & 1.0 \\
PDE5 $^{2}$ & 0.0066 & 0.0007 \\
PDE8 $^{3}$ & $>10$ & $>10$ \\
PDE9 $^{3}$ & $>10$ & 3.37 \\
PDE1 $^{4}$ & 0.396 & 0.180 \\
PDE2 $^{5}$ & $>10$ & $>10$ \\
PDE3 $^{5}$ & 17 & 2.5 \\
PDE4 $^{5}$ & 12 & 4.0 \\
PDE6 $^{6}$ & 0.049 & 0.011
\end{tabular}

PDE Phosphodiesterase. ${ }^{1}$ Human enzyme recombinant; ${ }^{2}$ Human platelet, purified; ${ }^{3}$ Mouse enzyme, recombinant; ${ }^{4}$ Bovine artery (aorta), purified; ${ }^{5}$ Bovine heart, purified: ${ }^{6}$ Bovine retina, purified. Data from reference 15

ideal therapy for ED include being noninvasive, safe, well tolerated, and effective in the broad population of ED patients (irrespective of age, severity, etiology and comorbidity) as well as in those who are more difficult to treat. Research focused in this area has lead to the development of new molecules that may provide better treatment options. The present review provides current information on vardenafil, a new PDE5 inhibitor.

Vardenafil is a highly selective, orally bioavailable PDE5 inhibitor that was designed specifically for the treatment of ED. The molecular entity was developed by Bayer AG. The clinical development plan and market development of the compound are a joint venture between Bayer and GlaxoSmithKline in all countries with the exception of Japan, where the joint venture is between Bayer and a Japanese company.

Vardenafil increases blood flow to the penis during sexual stimulation and, as a result, restores the potential ability to achieve and sustain an erection in men with ED. Increased blood flow is mediated by an increase in the levels of cyclic guanosine monophosphate (cGMP), a second messenger that is responsible, in part, for the smooth muscle relaxation that leads to vasodilation (15). Vardenafil selectively inhibits the enzyme PDE5 that is responsible for the hydrolysis of cGMP.

PDEs are found in many parts of the body and at least 11 different families of PDEs have been identified. Each has specific distribution patterns in selected organs and species. Therefore, high selectivity for PDE5 alone is important for minimizing the possibility of side effects that arise as a result of inhibition of other PDEs. Examples of possible side effects include heart rate increases and vasodilation that are attributed to inhibition of PDE1 and PDE3, or blue-green vision disturbances that are attributed to inhibition of PDE6.

The potency and selectivity of vardenafil, sildenafil and tadalafil (a third PDE5 inhibitor) have been compared in a number of different laboratories. Vardenafil specifically inhibited the hydrolysis of cGMP by human PDE5, and the $\mathrm{IC}_{50}$ (concentration required to inhibit enzyme activity by $50 \%$ )
TABLE 2

Selectivity ratios of PDE5 inhibitors

\begin{tabular}{lccc}
\hline PDE & Sildenafil & Vardenafil & Tadalafil \\
\hline PDE1 $^{1}$ & 80 & 500 & $>4450$ \\
PDE2 $^{1}$ & $>8570$ & 44,290 & $>14,800$ \\
PDE3 $^{1}$ & 4630 & $>7140$ & $>14,800$ \\
PDE4 $^{1}$ & 2190 & 43,570 & $>14,800$ \\
PDE5 $^{1}$ & 1 & 1 & 1 \\
PDE6 (rod $)^{1}$ & 11 & 25 & 187 \\
PDE6 $\left(\right.$ cone $^{1}$ & 10 & 4 & 193 \\
PDE7A $^{6}$ & 6090 & $>214,000$ & $>14,800$ \\
PDE8A $^{6}$ & 8510 & $>214,000$ & $>14,800$ \\
PDE9A $^{6}$ & 750 & 4150 & $>14,800$ \\
PDE10A $^{6}$ & 2800 & 21,200 & $>14,800$ \\
PDE11A $^{6}$ & 780 & 1160 & 5 \\
\hline
\end{tabular}

Selectivity ratio $=\left(I C_{50}\right.$ of $\left.P D E X\right) \div\left(I C_{50}\right.$ of PDE5), higher selectivity ratio means more selective for PDE5. PDE Phosphodiesterase. ${ }^{1}$ Human enzyme, purified: ${ }^{6}$ Human enzyme, recombinant. Data from reference 17

was determined to be $0.7 \mathrm{nM}$ (16). In addition, vardenafil showed minimal cross-reactivity with the other PDE subtypes. Tables 1 and 2 provide summaries of in vitro data.

In addition to purified enzyme and tissue preparations (16), oral doses of vardenafil have also been found to potentiate erectile responses in animal models $(16,18)$.

\section{CLINICAL PHARMACOKINETICS AND METABOLISM}

Vardenafil is rapidly absorbed following oral administration and reaches maximum plasma concentrations in less than $1 \mathrm{~h}$. The half-life is approximately 4 to $5 \mathrm{~h}$.

The mean absolute bioavailability of a $10 \mathrm{mg}$ dose is approximately $15 \%$, resulting from extensive first pass metabolism. Maximum observed plasma concentrations are usually reached between $30 \mathrm{~min}$ and $2 \mathrm{~h}$ (median $60 \mathrm{~min}$ ) after oral dosing in the fasted state.

An ED medication that fits into the lifestyle of a patient is likely to encourage willingness and comfort in using the medication. Accordingly, factors such as interactions with food or alcohol may be key in the patient's choice. The interaction of vardenafil with food was determined in a study (19) where healthy subjects were administered vardenafil under fasted conditions, or after ingesting meals of a high fat (breakfast, $57 \%$ fat) or moderate fat (dinner, $30 \%$ fat) content. Neither meal altered the pharmacokinetic parameters of vardenafil to a clinically significant degree, with the exception that the high fat meal delayed absorption (median $\mathrm{T}_{\max }$ ) by $1 \mathrm{~h}$ and reduced the mean peak plasma concentration $\left(\mathrm{C}_{\max }\right)$ by $18 \%$, with no change in the area under the plasma concentration versus time curve.

Vardenafil may, in some situations, be taken with alcohol, and therefore, the pharmacokinetic properties and hemodynamic changes associated with vardenafil were measured in conjunction with ethanol $(0.5 \mathrm{~g}$ of ethanol $/ \mathrm{kg}$ body weight in $200 \mathrm{~mL}$ orange juice) (20). Concomitant administration did not affect the pharmacokinetic properties of vardenafil or alcohol, and no clinically significant alterations were observed with regard to heart rate and blood pressure.

Vardenafil is metabolized in the liver by the cytochrome P450 (CYP) enzyme system, primarily by CYP3A4, and is eliminated mainly in feces. 
TABLE 3

Summary of specific drug interactions with vardenafil

\begin{tabular}{|c|c|c|c|}
\hline Drug class & & Interaction & Reference \\
\hline \multirow[t]{3}{*}{ Drugs that inhibit or are metabolized by CYP3A4 } & Ketoconazole & Increases bioavailability of vardenafil & Data on file \\
\hline & Erythromycin & Increases bioavailability of vardenafil & Data on file \\
\hline & Indinavir & Increases bioavailability of vardenafil & Data on file \\
\hline \multirow[t]{3}{*}{ Drugs that alter gastric $\mathrm{pH}$} & Maalox ${ }^{\circledR} 70$ & No interaction & (21) \\
\hline & Cimetidine & Marginal increase in bioavailability of vardenafil & (22) \\
\hline & Ranitidine & No interaction & \\
\hline \multirow[t]{3}{*}{ Drugs that affect blood pressure or heart rate } & Nitroglycerin & $\begin{array}{l}\text { Potential to cause exaggerated decrease in blood } \\
\text { pressure, increase in heart rate with the } 10 \mathrm{mg} \\
\text { vardenafil dose (changes were not statistically significant) }\end{array}$ & (23) \\
\hline & Nifedipine & No clinically significant hemodynamic effect & (24) \\
\hline & Digoxin & No interaction & (25) \\
\hline
\end{tabular}

CYP3A4 Cytochrome P450 enzyme system; Maalox 70 (Rhone-Poulenc Rorer GmbH, Germany)

\section{DRUG INTERACTIONS}

A comprehensive series of drug interaction studies have been conducted with vardenafil. These studies were designed to assess potential interactions between vardenafil and drugs that either inhibit or are metabolized by the CYP enzyme system, drugs with narrow therapeutic indexes, or drugs that may be used commonly by men with ED. A summary of the results of some of these studies is provided in Table 3. It is noted that, with the exception of nitroglycerin, vardenafil is not contraindicated with cardiovascular drugs (eg, nifedipine, antihypertensives, antiarrhythmics, etc). Like other PDE5 inhibitors, the concomitant administration of nitroglycerin with vardenafil could result in exaggerated reductions in blood pressure, and, therefore, vardenafil is contraindicated for those patients taking nitroglycerin in any form.

\section{EFFICACY IN PATIENTS WITH ED}

Initial phase II, randomized, placebo-controlled pharmacodynamic studies with vardenafil have been conducted in men with $\operatorname{ED}(26,27)$. Measurements of penile rigidity and tumescence were made at the base and tip of the penis using the RigiScan Ambulatory Tumescence Monitor (Dacomed Corp, USA) monitoring device. Compared with placebo, vardenafil significantly increased rigidity and duration of erections during visual sexual stimulation. Adverse events included headache, flushing and nasal congestion, but treatments were generally well-tolerated.

A follow-up, large-scale phase II study in men with mild to severe ED was conducted to evaluate the efficacy of vardenafil in an at-home setting. Measurements of efficacy used in this and subsequent phase III studies included the self-administered International Index of Erectile Function (IIEF) questionnaire, with a focus on the EF domain and the general assessment question (GAQ), a widely used parameter to determine treatment efficacy in improving erections. Additional efficacy measures in the phase III studies included the Sexual Encounter Profile (SEP) diary questions that determine success in vaginal penetration and intercourse completion.

In the phase II, large-scale study, 601 men with mild to severe ED were randomized to 12 weeks of treatment with 5 , 10 or $20 \mathrm{mg}$ vardenafil, or placebo (28). Primary endpoints were question 3 (vaginal penetration) and question 4 (mainte- nance of erection) of the IIEF. Changes from baseline for all doses of vardenafil were significantly greater for both endpoints. For the $20 \mathrm{mg}$ dose, $80 \%$ of patients experienced improved erections compared with $30 \%$ of those taking placebo, as measured by responses to the GAQ. Improvements with vardenafil were seen irrespective of age, etiology and baseline severity, and the effectiveness was maintained throughout the 12-week study period (29). The rates of adverse events (the most common being headache, dyspepsia and flushing) were highest in the first four weeks, and declined after that time or were stable throughout the duration of the study.

In recent months, much attention has been focused on the time taken for PDE5 inhibitors to exert the observed effect (ie, the length of time taken from drug ingestion to achieving an erection sufficient for sexual intercourse). This is referred to as 'time to onset of action' and clinical studies to measure this parameter are usually conducted in an at-home setting, with time measurements recorded with a stopwatch. The time to onset of action with vardenafil was assessed in a randomized, double-blind study, in which men with varying severity of ED were randomized to receive either vardenafil $20 \mathrm{mg}$ or placebo for a four-week period (30). The earliest time that men perceived an erection adequate for penetration and intercourse was determined for the first four doses. Subsequent intercourse was recorded in diaries. The proportion of men in each group was compared at the earliest elapsed time to an erection that was maintained sufficient for intercourse. No statistical differences were noted when subjective perception of an erection without confirmation of successful intercourse was used as the endpoint. More important, however, when subjective perception of an erection was confirmed by intercourse completion, a greater proportion of men responded on vardenafil. A statistically superior response to vardenafil was observed from $25 \mathrm{~min}$ down to and including $16 \mathrm{~min}$ (34\% vardenafil versus $24 \%$ placebo, $\mathrm{P}=0.013)$. At $25 \mathrm{~min}, 48 \%$ of men on vardenafil responded versus $30 \%$ on placebo $(\mathrm{P}<0.0001)$. These results show that onset of action of vardenafil is recognized as early as 16 min after patients ingest the medication.

\section{PHASE III STUDIES}

The North American phase III study (31) was conducted in 54 centres in Canada and the United States. Patients included in this study had ED that varied in etiology and severity. Comorbidities included hypertension, prostatic hyperplasia, 


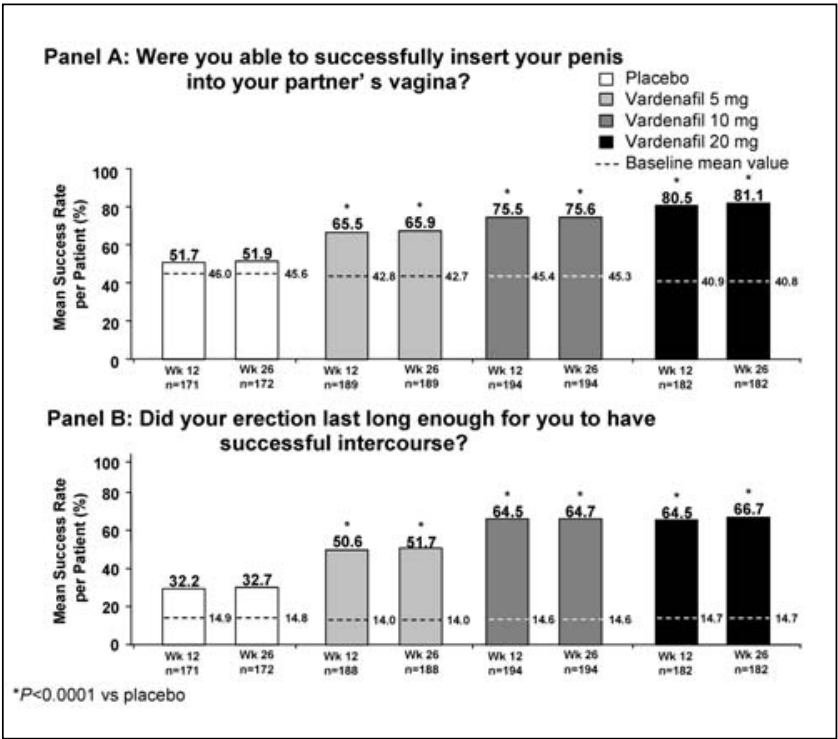

Figure 1) A Mean success rates per patient describing ability to penetrate partner; B Mean success rates per patient describing ability to maintain erections sufficiently to have successful intercourse. Adapted with permission from reference 31

type 2 diabetes mellitus, depression and cardiovascular diseases. Patients were randomized to 26 weeks of fixed-dose treatment with either placebo or vardenafil 5,10 or $20 \mathrm{mg}$. Vardenafil significantly increased the EF domain scores compared with placebo in this broad range of men. Of those completing 26 weeks of treatment, erections were noted by up to $85 \%$ of men (20 mg vardenafil), compared with $28 \%$ for placebo $(\mathrm{P}<0.0001)$. Also, it improved patients' ability to penetrate (SEP diary question 2) and to maintain erections to successful completion of intercourse (SEP diary question 3 ). For example, in patients taking $20 \mathrm{mg}$ vardenafil, the per-patient success rate of penetration doubled from $41 \%$ at baseline to $80 \%$ at week 12; the ability to maintain an erection for successful intercourse increased more than four-fold from $15 \%$ at baseline to $65 \%$ at week 12 (all $\mathrm{P}<0.0001$ versus placebo; placebo rate $32 \%)$. These improvements were observed at both 12 weeks and 26 weeks. These data are shown graphically in Figure 1.

Adverse events were transient and generally mild to moderate with headache, cutaneous flushing, rhinitis and dyspepsia as the most frequent complaints. Table 4 summarizes the incidence of treatment-emergent adverse events from this study.

Therapeutic reliability, or consistency of effect over time, may be a key feature for patient satisfaction, especially in the area of sexual dysfunction. Reliability of vardenafil was analyzed retrospectively in the North American Pivotal Study (32). The success rates for vaginal penetration and successful intercourse were determined at the first attempt. Of those who were successful in the first attempt, their success rate at subsequent attempts was determined up to week 12 . Vardenafil reliably improved $\mathrm{EF}$ in patients during their first attempt and during subsequent attempts. The mean per-patient vaginal penetration success rate over the 12 weeks of treatment reached $91 \%$ in men in the $20 \mathrm{mg}$ treatment group. More importantly, vardenafil also showed good reliability in the mean per-patient success rate for successful intercourse over
TABLE 4

Incidence of treatment-emergent adverse events during six months of study in which incidence is greater than $5 \%$ in any treatment group (safety population) and greater than placebo (30).

\begin{tabular}{lcccc}
\hline & $\begin{array}{c}\text { Placebo } \\
\mathbf{n}(\%) \\
\mathbf{n = 1 8 2}\end{array}$ & $\begin{array}{c}\mathbf{5} \mathbf{~} \mathbf{~ g} \\
\mathbf{n = 1 9 3}\end{array}$ & $\mathbf{1 0} \mathbf{~} \mathbf{n g}$ & $\mathbf{2 0} \mathbf{~ m g}$ \\
$\mathbf{n = 1 9 9}$ & $\mathbf{n = 1 8 8}$ \\
\hline Headache & $8(4)$ & $19(10)$ & $44(22)$ & $40(21)$ \\
Rhinitis & $9(5)$ & $17(9)$ & $27(14)$ & $32(17)$ \\
Cutaneous flushing & $0(0)$ & $9(5)$ & $20(10)$ & $24(13)$ \\
Dyspepsia & $1(<1)$ & $2(1)$ & $8(4)$ & $12(6)$ \\
Sinusitis & $2(1)$ & $10(5)$ & $6(3)$ & $9(5)$ \\
Accidental injury & $5(3)$ & $11(6)$ & $7(4)$ & $8(4)$ \\
Flu syndrome & $2(1)$ & $10(5)$ & $5(3)$ & $3(2)$ \\
\hline
\end{tabular}

the 12 weeks of treatment, with values reaching $85 \%$ in the $20 \mathrm{mg}$ treatment group.

Other parameters such as improvements in the EF score to a level that is rated as normal in the EF domain of the IIEF (ie, IIEF-EF domain score of $\geq 26$ ) were measured over the 12-week period. For each of the four severity categories (mild, mild to moderate, moderate or severe at baseline), more patients 'returned to normal' with vardenafil compared with placebo. For example, with $20 \mathrm{mg}$ vardenafil, $79 \%$ of patients with mild $\mathrm{ED}$ at baseline returned to normal (compared with 21\% in the placebo group), and $39 \%$ of patients with severe $\mathrm{ED}$ at baseline returned to normal (compared with only $4 \%$ in the placebo group) (31).

In addition to the ability of a drug to work the first time it is tried and give consistent efficacy over time, there are also patient expectations that a drug will be effective over a long period of time, and that tolerability will not be affected. The long term efficacy and safety of vardenafil $(10 \mathrm{mg}$ and $20 \mathrm{mg}$ ) were tested in a one-year randomized, double-blind study (33). The rate of successful intercourse, which was approximately $15 \%$ at baseline, increased greatly within the first four-week period. At the end of one year, the incidence of successful intercourse remained consistently high at $81 \%$ for the vardenafil $10 \mathrm{mg}$ group, and $84 \%$ for the vardenafil $20 \mathrm{mg}$ group. In addition, the drug was well tolerated when taken over time. The overall rate of adverse events leading to treatment discontinuation was only $5 \%$ in the safety population receiving vardenafil $10 \mathrm{mg}$ and $6 \%$ in patients receiving vardenafil $20 \mathrm{mg}$ during the one-year period.

The data from the North American pivotal study $(\mathrm{n}=805)$ were pooled with another pivotal study conducted in Europe $(n=674)$, and the combined group was analyzed to verify that vardenafil indeed has a similar therapeutic effect in various subpopulations with ED. Efficacy of vardenafil in this pooled population was assessed based on a number of factors including etiology (organic, psychogenic or mixed) (34), severity of ED at baseline (35), and in special population groups such as the elderly (36). In addition, efficacy was analyzed based on those who had specific comorbidities (such as hypertension, hyperlipidemia and diabetes mellitus) (37) and those who were taking antihypertensive medications such as diuretics and beta-blockers (38). In each of these subpopulations, vardenafil 
significantly improved indices of EF compared with placebo, thereby providing evidence of efficacy in a broad range of men with ED. The drug was well tolerated, with only minimal blood pressure changes regardless of whether patients were taking antihypertensive medications. In addition, no clinically significant elevations in heart rate were observed in the vardenafiltreated patients.

Due to the combination of vascular and neurogenic components of the disease, certain patient populations are found to be more difficult to treat than others. For instance, patients with diabetes have a higher incidence of ED but are generally less responsive to available oral ED therapies. To determine the efficacy of vardenafil in this hard to treat population, a doubleblind, randomized, multicentre, placebo-controlled study of vardenafil was conducted in Canada and the United States (39). Patients were randomized to 12 weeks of treatment with either placebo, or 10 or $20 \mathrm{mg}$ vardenafil. Both doses significantly improved rates of maintenance of erection to intercourse completion, penetration rates and $\mathrm{EF}$ domain scores, compared with placebo. The GAQ responder rate was $72 \%$ for the $20 \mathrm{mg}$ group and was statistically greater than that of the placebo group (13\%; $\mathrm{P}<0.0001)$. Adverse events were generally mild to moderate. A follow-on extension study (additional 12 weeks of treatment) showed that the improved rates of erection maintenance to completion of intercourse, IIEF domain scores, and GAQ scores were sustained for a further three months (40).

ED is a common complication following prostatectomy. A Canadian-led multicentre trial was undertaken to determine if vardenafil could improve EF in men who had undergone nerve-sparing radical prostatectomy (41). In this double-blind, placebo-controlled study, men who had ED after having nervesparing radical retropubic prostatectomy within the previous five years were randomized to a three-month treatment with placebo, or vardenafil 10 or $20 \mathrm{mg}$. As would be expected with this type of surgery, mean baseline scores of the IIEF-EF domain in the three treatment arms indicated severe ED (9.1 to 9.3). After treatment with vardenafil, rates of partner penetration and erection maintenance were increased $(\mathrm{P}<0.0001$ for all primary efficacy measures), irrespective of baseline severity. Also, IIEF-EF domain scores were significantly improved (15.3 for $10 \mathrm{mg}$ and $20 \mathrm{mg}$, versus 9.2 for placebo, $\mathrm{P}<0.0001)$. Within this particular study, two additional scales were analyzed, the Duke Health Profile and the Centre for Epidemiologic Studies Depression Scale (CES-D), as it is known that ED and quality of life are often negatively associated (42). Overall, vardenafil $20 \mathrm{mg}$ improved depression domain scores in the Duke Health Profile $(\mathrm{P}<0.05$ versus placebo). In the subgroup of men with CES-D scores indicative of depression at baseline, vardenafil $20 \mathrm{mg}(\mathrm{n}=14)$ significantly improved scores versus placebo $(n=10)(10.8$ versus 17.9; $\mathrm{P}<0.001)$. The most common adverse events were headache, cutaneous flushing and rhinitis, and were mild to moderate.

\section{CARDIOVASCULAR SAFETY}

PDE5 inhibitors are known to cause vasodilation by their action at the smooth muscle. Therefore, there exists the possibility that PDE5 inhibitors may affect the cardiovascular hemodynamics and compromise the safety profile of these agents.

The cardiovascular safety profile of vardenafil was analyzed in five placebo-controlled, randomized trials that included a total number of 2605 patients. Studies were 12 to 26 weeks in
TABLE 5

Incidence rates of treatment-emergent, potentially clinically significant vital sign abnormalities* 11 min to $5 \mathrm{~h}$ after study medication ingestion - overall population valid for safety (42)

\begin{tabular}{|c|c|c|}
\hline Vital sign abnormality & $\begin{array}{l}\text { Placebo } \\
\text { (\%) } n=793\end{array}$ & $\begin{array}{l}\text { Vardenafil } \\
(\%) n=1812\end{array}$ \\
\hline \multicolumn{3}{|l|}{ Supine } \\
\hline $\begin{array}{l}\text { - SBP less than or equal to } 90 \mathrm{mmHg} \text { and } \\
\text { decrease from baseline greater than or } \\
\text { equal to } 20 \mathrm{mmHg}\end{array}$ & $0 / 167(0.0)$ & $3 / 469(0.6)$ \\
\hline $\begin{array}{l}\text { - DBP less than or equal to } 50 \mathrm{mmHg} \text { and } \\
\text { decrease from baseline greater than or } \\
\text { equal to } 15 \mathrm{mmHg}\end{array}$ & $0 / 167(0.0)$ & $0 / 469(0.0)$ \\
\hline $\begin{array}{l}\text { - HR greater than } 120 \mathrm{bpm} \text { and increase } \\
\text { from baseline greater than or equal to } \\
15 \mathrm{bpm}\end{array}$ & $0 / 167(0.0)$ & $0 / 469(0.0)$ \\
\hline \multicolumn{3}{|l|}{ Standing } \\
\hline $\begin{array}{l}\text { - SBP less than or equal to } 90 \mathrm{mmHg} \text { and } \\
\text { decrease from baseline greater than or } \\
\text { equal to } 20 \mathrm{mmHg}\end{array}$ & $0 / 183(0.0)$ & $4 / 520(0.8)$ \\
\hline $\begin{array}{l}\text { DBP less than or equal to } 50 \mathrm{mmHg} \text { and } \\
\text { decrease from baseline greater than or } \\
\text { equal to } 15 \mathrm{mmHg}\end{array}$ & $0 / 183(0.0)$ & $1 / 520(0.2)$ \\
\hline $\begin{array}{l}\text { - HR greater than } 120 \mathrm{bpm} \text { and increase } \\
\text { from baseline greater than or equal to } 15 \mathrm{bpm}\end{array}$ & $1 / 183(0.6)$ & $0 / 520(0.0)$ \\
\hline
\end{tabular}

bpm beats per minute; DBP Diastolic blood pressure; HR Heart rate; SBP Systolic blood pressure. *Definitions recommended by the United States Food and Drug Administration

duration. In addition to general safety assessments, cardiovascular safety assessments such as supine and standing systolic and diastolic blood pressure (SBP and DBP, respectively), and heart rate measurements were made (43). The pooled group included patients from the broad population studies as well as those from the diabetes and prostatectomy studies. In some patient groups, supine and standing SBP, DBP and heart rate measurements were also made $11 \mathrm{~min}$ to $5 \mathrm{~h}$ postdose (the time interval between absorption and elimination phases of vardenafil). As expected from the mechanism of action, within the short window up to $5 \mathrm{~h}$, there were small, transient decreases in blood pressure and increases in heart rate relative to placebo. However, overall, vardenafil did not significantly alter mean blood pressure or heart rate relative to placebo. As shown in Table 5, the overall incidence of clinically significant changes in vital signs was very small.

One or more antihypertensive medications was used by $40 \%$ and $42 \%$ of the placebo- and vardenafil-treated groups, respectively. Concomitant use of antihypertensive medications, overall or within the different classes (angiotensin-converting enzyme inhibitors, calcium antagonists, beta-blockers, diuretics, alpha-blockers and angiotensin receptor blockers), resulted in no or small incremental decreases in SBP and DBP that were generally similar in magnitude across the classes. There were no notable differences between placebo and vardenafil treatment groups with respect to treatment-emergent electrocardiogram findings. There were very few cardiovascular adverse events in the studies, and the incidence of these events was similar for patients receiving placebo or vardenafil. Overall, the results from the pooled analysis indicate that vardenafil has a favourable cardiovascular safety profile. 
ED is common among men with coronary artery disease (CAD) and there is a small but finite risk of developing ischemia with sexual activity in these patients. A multicentre study was conducted in patients with stable cardiac ischemia to evaluate the effect of vardenafil in patients undergoing an exercise treadmill test during physical exercise at a level similar to or greater than required during sexual activity (44). In this study, 41 men with stable ischemic CAD received single doses of vardenafil $10 \mathrm{mg}$ or placebo, and an exercise treadmill test was performed $1 \mathrm{~h}$ postdose at the expected time of maximal drug exposure. Treadmill exercise time, time to angina pectoris (first awareness), and time to ST-segment depression $1 \mathrm{~mm}$ change from baseline were measured. Relative to placebo, vardenafil did not alter the total exercise treadmill time and time to awareness of angina pectoris. Moreover, time to ST-segment depression was slightly improved (by approximately 15\%) by vardenafil compared to placebo $(\mathrm{P}=0.0004)$. In addition, there were no untoward hemodynamic effects of exercise because changes in heart rate, blood pressure and rate-pressure product were similar in both vardenafil- and placebo-treated patients. Vardenafil was well tolerated with the most common adverse events (headache, flushing) being mild to moderate in nature. These results show that vardenafil $10 \mathrm{mg}$ does not affect the ability of patients with stable CAD to exercise at a level similar to that usually required for sexual intercourse.

\section{CONCLUSIONS}

The results of epidemiological studies reveal that the prevalence of ED will continue to rise over the next quarter century

\section{REFERENCES}

1. Feldman HA, Goldstein I, Hatzichristou DG, Krane RJ, McKinlay JB. Impotence and its medical and psychosocial correlates: Results of the Massachusetts Male Aging Study. J Urol 1994;151:54-61.

2. Braun M, Wassmer G, Klotz T, Reifenrath B, Mathers M, Engelmann U. Epidemiology of erectile dysfunction: Results of the 'Cologne Male Survey'. Int J Impot Res 2000;12:305-11.

3. Morillo LE, Diaz J, Estevez E, et al. Prevalence of erectile dysfunction in Colombia, Ecuador, and Venezuela: A population based study. Int J Impot Res 2002;14(Suppl 2):S10-8.

4. Brock G. Erectile dysfunction educational forum - 1. Can J Urol 2001;8:1416-8.

5. Auld RB, Brock G, Members of the Canadian Male Sexual Health Council. Sexuality and erectile dysfunction. Results of a national survey. J Sex Reprod Med 2002;2:50-4.

6. Ward RA, Raiche P, Fidler HA. Results of a national needs assessment for continuing medical education of family physicians related to erectile dysfunction and/or male sexual dysfunction. J Sex Reprod Med 2002;2:55-60.

7. Vinik A, Richardson D. Erectile dysfunction in diabetes. Diab Rev 1998;6:16-33.

8. Burchardt M, Burchardt T, Baer L, et al. Hypertension is associated with severe erectile dysfunction. J Urol 2000;164:1188-91.

9. Talcott JA, Rieker P, Propert KJ, et al. Patient-reported impotence and incontinence after nerve-sparing radical prostatectomy. J Nat Can Inst 1997;89:1117-23

10. Mantz CA, Song P, Farhangi E, et al. Potency probability following conformal megavoltage radiotherapy using conventional doses for localized prostate cancer. Int J Radiat Oncol Biol Phys 1997;37:551-7.

11. Brock GB. A simplified approach to the treatment of erectile dysfunction - based on the Canadian Urology Association Erectile Dysfunction Guidelines. J Sex Reprod Med 2002;2(2):61-5.

12. Hatzichristou D. Sildenafil citrate: Lessons learned from 3 years of clinical experience. Int J Impot Res 2002;14(Suppl 1):S43-52.

13. Padma-Nathan H. A 4-year update on the safety of sildenafil citrate (Viagra ${ }^{\circledR}$ ). Urology 2002;60(Suppl 2B):67-90.

14. Seftel AD. Challenges in oral therapy for erectile dysfunction. J Androl 2002;23:729-36. due to increased longevity, as well as an increased likelihood of comorbid conditions that predispose to ED. Although both oral and local therapies are currently available, many men suffering from ED are not completely satisfied with existing treatments and are looking for new options. Vardenafil is highly selective and is the most potent PDE5 inhibitor in vitro. Results from the rigorous clinical trial program show substantial improvements in validated efficacy measures of EF in the broad range of men with $\mathrm{ED}$, and across a wide range of severity, etiology and age. Vardenafil also improves EF in men whose ED is considered difficult to treat (ie, men with diabetes or postradical prostatectomy). Long term studies reveal that vardenafil maintains efficacy over 12 months and has a safety profile characteristic of PDE5 inhibitors, with the most frequent adverse events being transient headache, flushing and rhinitis of mild to moderate intensity.

Together with strong efficacy and cardiovascular safety, vardenafil also provides the key features of reliability, fast onset of action and minimal interaction with food and alcohol, and, thus, offers a valuable treatment option to the large population of men with ED. Ultimately, these factors, combined with the postmarketing experience, will aid patients and physicians in choosing the PDE5 inhibitor that best suits their needs.

ACKNOWLEDGEMENTS: Dr Pommerville has participated in clinical trials sponsored by, and serves on advisory boards for, Pfizer, Lilly and Bayer/GlaxoSmithKline. He would like to thank Dr Lynne de Souza and the medical group at Bayer who supplied current information on vardenafil.

15. Lue TF. Erectile dysfunction. N Engl J Med 2000;342:1802-13.

16. Saenz de Tejada I, Angulo J, Cuevas P, et al. The phosphodiesterase inhibitory selectivity and the in vitro and in vivo potency of the new PDE5 inhibitor vardenafil. Int J Impot Res 2001;13:282-90.

17. Gbekor E, Bethell S, Fawcett L, Mount N, Phillips S. Phosphodiesterase 5 inhibitor profiles against all human phosphodiesterase families: Implications for use as pharmacological tools. Eur Urol 2002;1(Suppl 1):244. (Abst)

18. Bischoff E, Niewoehner U, Haning H, Es Sayed M, Schenke T, Schlemmer KH. The oral efficacy of vardenafil hydrochloride for inducing penile erection in a conscious rabbit model. J Urol 2001;165:1316-8.

19. Rajagopalan P, Mazzu A, Xia C, Dawkins R, Sundaresan P. Effect of high-fat breakfast and moderate-fat evening meal on the pharmacokinetics of vardenafil, a potent, highly selective PDE-5 inhibitor for the treatment of erectile dysfunction. Pharmacotherapy 2002;22:1365.(Abstr)

20. Bauer R-J, Rohde G, Wensing G. The interaction of alcohol with vardenafil, a potent and highly selective phosphodiesterase type 5 inhibitor. Pharmacotherapy 2002;22:418. (Abst)

21. Rohde G, Wensing G, Sachse R. The pharmacokinetics of vardenafil, a new selective PDE5 inhibitor, are not affected by the antacid Maalox 70 . Pharmacotherapy 2001;21:1254.(Abstr)

22. Rohde G, Wensing G, Unger S, Sachse R. The pharmacokinetics of vardenafil, a new selective PDE5 inhibitor, is minimally affected by coadministration with cimetidine or ranitidine. Pharmacotherapy 2001:21:1254. (Abst)

23. Mazzu A, Nicholls A, Zinny M. Vardenafil, a new selective PDE-5 inhibitor, interacts minimally with nitroglycerin in healthy middle-aged male subjects. Int J Impot Res 2001;13(Suppl 5):S64 (Abst)

24. Rohde G, Jordaan PJ. Influence of vardenafil on blood pressure and pharmacokinetics in hypertensive patients on nifedipine therapy. Pharmacotherapy 2002;22:418. (Abst)

25. Rohde G, Bauer R-J, Unger S, Ahr G, Wensing G, Kuhlmann J. Vardenafil, a new selective PDE5 inhibitor, produces no interaction with digoxin. Pharmacotherapy 2001;21:1254. (Abst)

26. Klotz T, Sachse R, Heidrich A, et al. Vardenafil increases penile rigidity 
and tumescence in erectile dysfunction patients: A RigiScan and pharmacokinetic study. World J Urol 2001;19:32-9.

27. Stark S, Sachse R, Liedl T, et al. Vardenafil increases penile rigidity and tumescence in men with erectile dysfunction after a single oral dose. Eur Urol 2001:40:181-90.

28. Porst H, Rosen R, Padma-Nathan H, et al. The efficacy and tolerability of vardenafil, a new, oral, selective phosphodiesterase type 5 inhibitor in patients with erectile dysfunction: the first at-home clinical trial. Int J Impot Res 2001;13:192-9.

29. Young J, Auerback S, Porst H. Vardenafil, a new selective PDE5 inhibitor, significantly improved all IIEF domains and showed a favorable safety profile in patients with erectile dysfunction over 12 weeks. J Urol 2001;165(Suppl):224. (Abst)

30. Padma-Nathan H, Kaufman J, Taylor T. Earliest time of onset of erections with vardenafil determined in an at-home setting. J Androl 2003;24(Annual Mtg Suppl):48. (Abst)

31. Hellstrom WJG, Gittelman M, Karlin G, et al. Vardenafil for treatment of men with erectile dysfunction: Efficacy and safety in a randomized, double-blind, placebo-controlled trial. J Androl 2002;23:763-71.

32. Valiquette L, Hellstrom W, Gittelman M, et al. Vardenafil provides reliable efficacy over time in men with erectile dysfunction. Int J Impot Res 2002;14(Suppl 3):S88. (Abst)

33. Saenz de Tejada I, Glina S, Becher E, Ulbrich E and the Vardenafil Study Group. Long-term efficacy and safety of vardenafil: A 12 month double-blind study. Int J Impot Res 2002;14(Suppl 3):S35. (Abst)

34. Donnatucci C, Eardley I, McVary KT, Thibonnier M. Vardenafil improves erectile function regardless of etiology or baseline severity in men with erectile dysfunction. J Urol 2002;167(Suppl):178. (Abst)

35. Padma-Nathan H, Eardley I, Collins O, Segerson T. Vardenafil restores normal functioning to men with erectile dysfunction. J Urol 2002;167(Suppl):177. (Abst)

36. Donnatucci C, Karlin G, Goldfischer E, Cohen S, Thibonnier M. Influence of age on the efficacy and safety of vardenafil, a novel phosphodiesterase-5 inhibitor, for the treatment of erectile dysfunction. J Amer Ger Soc 2002;50(4 Suppl):S107. (Abst)

37. Goldfischer E, Eardley I, Segerson T. Vardenafil improves erectile function in men with significant comorbidities associated with erectile dysfunction (ED). J Urol 2002;167(Suppl):178. (Abst)

38. Padma-Nathan H, Porst H, Eardley I, Thibonnier M. Efficacy and safety of vardenafil, a selective phosphodiesterase 5 inhibitor, in men with erectile dysfunction on antihypertensive therapy. Am J Hypertens 2002;15:48A. (Abst)

39. Goldstein I, Young JM, Fischer J, et al. Vardenafil, a new phosphodiesterase type 5 inhibitor, in the treatment of erectile dysfunction in men with diabetes. Diabetes 2001;50(Suppl 2):A114. (Abst)

40. Goldstein I, Young J, Segerson T, Thibonnier M. Long-term efficacy and safety of vardenafil in diabetic men with erectile dysfunction. Diabetes 2002;51(Suppl 2):A98. (Abst)

41. Brock G, Taylor T, Seger M, Vardenafil PROSPECT Group Canada. Efficacy and tolerability of vardenafil in men with erectile dysfunction following radical prostatectomy. Eur Urol 2002;1(Suppl 1):152. (Abst)

42. Brock G, Nehra A, Lipshultz L, Gleave M, Seger M, Padma-Nathan H. Influence of vardenafil on erectile dysfunction (ED) and depressive symptoms post radical prostatectomy. Int J Impot Res 2002:14(Suppl 3):97. (Abst)

43. Kloner RA, Mohan P, Norenberg C, Pomerantz K, Segerson T, Glasser S. Cardiovascular safety of vardenfil, a potent, highly selective PDE5 inhibitor in patients with erectile dysfunction; An analysis of five placebo-controlled clinical trials. Pharmacotherapy 2002;22:1371. (Abst)

44. Thadani U, Smith W, Nash S, et al. The effect of vardenafil, a potent and highly selective phosphodiesterase-5 inhibitor for the treatment of erectile dysfunction, on the cardiovascular response to exercise in patients with coronary artery disease. J Am Coll Cardiol 2002:40:2006-12. 